\title{
Altered ageing behaviour of a nanostructured Mg-8.2Gd-3.8Y-1.0Zn- 0.4Zr alloy processed by high pressure torsion
}

\author{
W.T. Sun ${ }^{1}$, X.G. Qiao ${ }^{1 *}$, M.Y. Zheng ${ }^{1 *}$, C. Xu ${ }^{2}$, S. Kamado ${ }^{2}$, X.J. Zhao ${ }^{3}$, H.W. Chen ${ }^{3}$, N. Gao ${ }^{4}$, \\ M.J. Starink ${ }^{4}$ \\ ${ }^{1}$ School of Materials Science and Engineering, Harbin Institute of Technology, Harbin 150001, PR China \\ ${ }^{2}$ Department of Mechanical Engineering, Nagaoka University of Technology, Nagaoka 940-2188, Japan \\ ${ }^{3}$ College of Materials Science and Engineering, Chongqing University, Chongqing 400044, PR China \\ ${ }^{4}$ Materials Research Group, Faculty of Engineering and the Environment, University of Southampton, \\ Southampton SO17 1BJ, UK \\ * zhenghe@ @it.edu.cn, Tel.: +86451 86402291, fax: +8645186413922 \\ *xgqiao@ hit.edu.cn, Tel.: +86 451 86402291, fax: +86 45186413922
}

\section{Abstract:}

In this study, the ageing behaviour of a nanostructured $\mathrm{Mg}-8.2 \mathrm{Gd}-3.8 \mathrm{Y}-1.0 \mathrm{Zn}-0.4 \mathrm{Zr}$ (wt.\%) alloy produced by solution treatment followed by high pressure torsion (HPT) was systematically investigated using hardness testing, high resolution high-angle annular dark-field scanning transmission electron microscopy (HAADF-STEM), elemental mapping, X-ray diffraction (XRD) and XRD line broadening analysis. The HPT-deformed alloy exhibits an ageing response that produces a higher peak-aged hardness at lower temperature and shorter ageing time as compared to the same alloy aged after conventional thermomechanical processing. The HAADF-STEM and elemental mapping reveal extensive segregation of solute atoms along grain boundaries during ageing. A model is developed which shows that the main structures causing hardening for peak-aged samples are the grain boundaries and the segregation of solute atoms formed along grain boundaries. The metastable $\beta^{\prime}$ phase precipitates, which form on ageing of conventionally processed Mg-Gd-Y-Zn-Zr alloy samples, do not form in 
the present aged samples, and instead equilibrium $\beta-\mathrm{Mg}_{5}(\mathrm{RE}, \mathrm{Zn})$ phase forms on overageing. This altered precipitation behaviour is attributed to the high defect density (e.g. grain boundaries, dislocations and vacancies) introduced by HPT, leading to enhanced diffusion of solutes. The present processing produces an alloy that has a hardness of $\sim 145 \mathrm{HV}$. A model of strengthening indicates that whilst grain boundary strengthening provides the largest contribution to strengthening, it is the additional solid solution hardening, cluster hardening, and dislocation hardening that provide the main factors that caused the hardness to surpass that of other bulk processed Mg alloys studied to date.

Key words: High pressure torsion; Mg-RE alloy; Ageing behaviour; Grain boundary segregation; Nano precipitates.

\section{Graphical Abstract:}

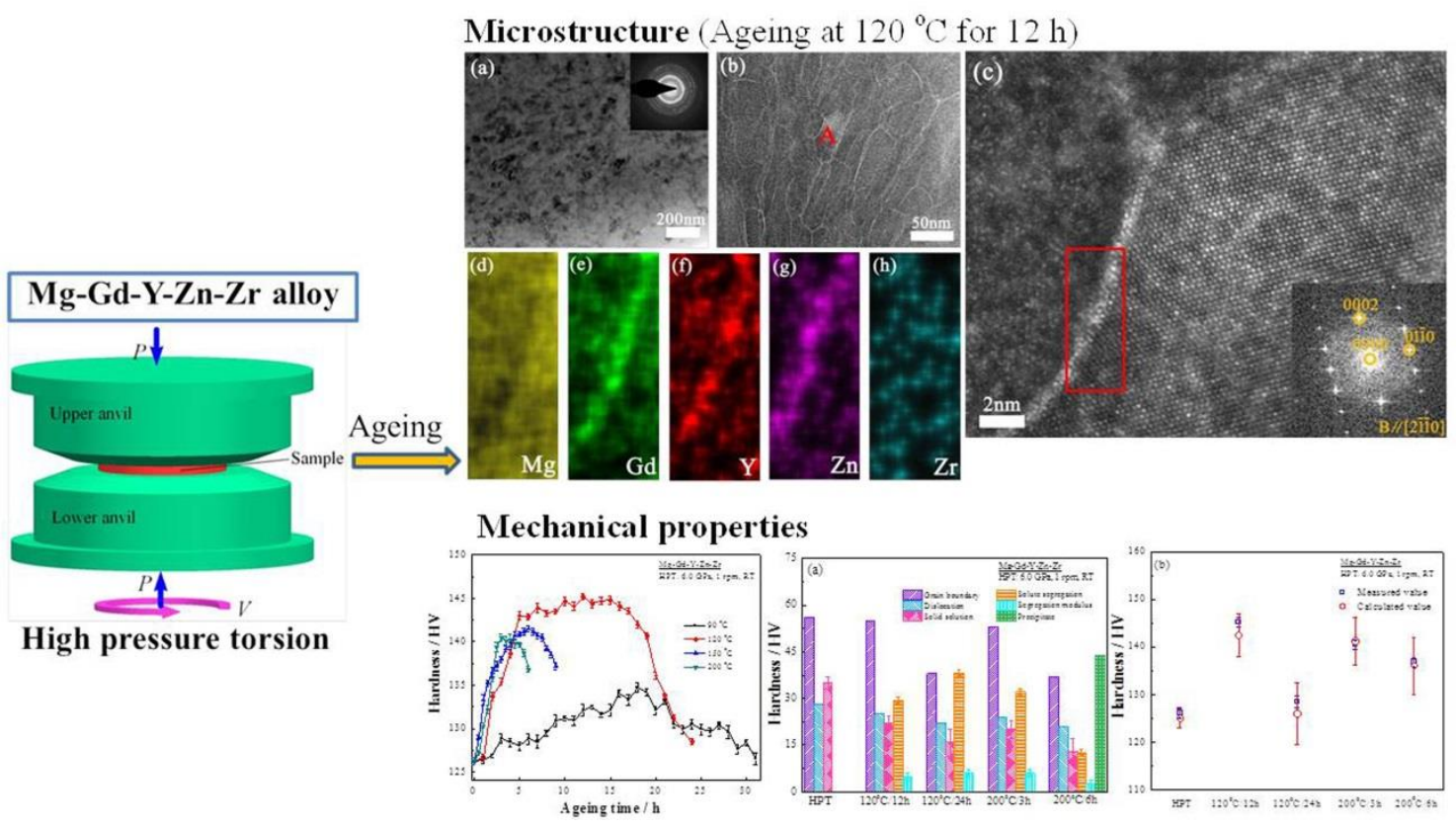

\section{Introduction}

In recent years, the addition of rare earth elements (RE) into magnesium alloys has 
provoked scientific and industrial interest due to the combination of low density with outstanding mechanical properties at both room and elevated temperatures [1-4]. Grain refinement is an effective approach to improve strength of magnesium alloys whilst retaining reasonable ductility [5].

Several techniques based on severe plastic deformation (SPD) are effectively used to fabricate an ultrafine-grained structure in $\mathrm{Mg}$ alloys to provide further enhanced strength in combination with a reasonable ductility [6-8]. Amongst the SPD procedures, high pressure torsion (HPT) is especially effective to produce bulk nanostructured $\mathrm{Mg}$ alloys because an extremely large torsional straining together with high hydrostatic pressure of several GPa can be imposed by HPT at ambient temperature $[9,10]$. Strengthening due to SPD is generally caused by grain refinement and dislocation hardening.

For most Mg-RE based alloys that contain substantial amounts of soluble alloying elements, ageing treatment is another effective approach to strengthen the alloys. Grain boundaries (GBs) usually play an important role in promoting heterogeneous precipitation [11], and the large amount of GBs created by HPT processing may lead to different ageing behaviours of the nanostructured Mg alloys. Therefore HPT-deformed supersaturated Mg-RE alloys that are aged after HPT may develop unusual mechanical properties. Up to now, very few reports have focused on the ageing response of nanograined Mg alloys processed by HPT. VlČek et al. [12] investigated the isochronal annealing behavior of solution-treated binary $\mathrm{Mg}-13 \mathrm{~Tb}$ (wt.\%) and ternary $\mathrm{Mg}-3.6 \mathrm{~Tb}-$ 2.1Nd (wt.\%) alloys processed by HPT at room temperature for 5 turns. On ageing at 
$200^{\circ} \mathrm{C}$ a high peak hardness of $\sim 130 \mathrm{HV}$ was achieved and based on positron lifetime data it was speculated that coherent $\beta^{\prime \prime}$ precipitates caused the hardening (no direct microcopy evidence of any structures was presented). The research by Dobatkin et al. [13] indicated that the strength of HPT-processed Mg-4.7Y-4.6Gd-0.3Zr (wt.\%) alloy with a partially nanocrystalline structure could be further improved by ageing at 175 and $200^{\circ} \mathrm{C}$. They ascribed the age hardening to fine precipitates, however, they failed to reveal or identify any precipitate in the HPT-deformed and subsequently aged alloy presumably due to the nanoscale dimensions of the constituents and a high dislocation density.

In the present research, a solution-treated $\mathrm{Mg}-8.2 \mathrm{Gd}-3.8 \mathrm{Y}-1.0 \mathrm{Zn}-0.4 \mathrm{Zr}$ (wt.\%) alloy was processed by HPT at ambient temperature, and the ageing response of the HPT-deformed alloy at various temperatures is systematically investigated. The aim is to both shed light on the mechanisms of age hardening of nanostructured Mg-RE alloys as well as to investigate potential for producing $\mathrm{Mg}$ alloys with improved strength in combination with a refined nanostructure that has potential for high ductility.

\section{Experimental procedures}

A direct-chill cast Mg-8.2Gd-3.8Y-1.0Zn-0.4Zr (wt.\%) alloy was homogenized at $510{ }^{\circ} \mathrm{C}$ for $12 \mathrm{~h}$, followed by immediate quenching into warm water at $\sim 60{ }^{\circ} \mathrm{C}$ [14]. Disks with a diameter of $10.0 \mathrm{~mm}$ and a thickness of $1.0 \mathrm{~mm}$ for HPT processing were machined from the ingot. After grinding with abrasive papers on both sides to a final thickness of $\sim 0.85 \mathrm{~mm}$ with parallel broad surfaces, the disks were subjected to HPT processing with 10 turns at room temperature under an imposed pressure of $6.0 \mathrm{GPa}$ 
and a rotational speed of $1 \mathrm{rpm}$ [15]. The HPT-processed disks were aged at $90{ }^{\circ} \mathrm{C}, 120$ ${ }^{\circ} \mathrm{C}, 150{ }^{\circ} \mathrm{C}$ and $200{ }^{\circ} \mathrm{C}$ for a range of different time periods, followed by quenching in cold water.

The effect of ageing at different temperatures was evaluated by the evolution of Vickers hardness using a Zwick microhardness tester under a static load of 500 gf for $15 \mathrm{~s}$. Each reported value represents the average of 8 indentations all at the half-radius positions of the disk. The variation of electrical conductivity $g$ with ageing time at 120 ${ }^{\circ} \mathrm{C}$ was measured by a Sigma 2008B Eddy current conductivity meter. Each measurement was repeated 10 times and an average conductivity value was determined.

The TEM observation was carried out at the half-radius position of HPT-processed disks using a FEI Talos F200X transmission electron microscope (TEM) operated at $200 \mathrm{kV}$ accelerating voltage. TEM samples were thin disks with a diameter of $3.0 \mathrm{~mm}$ punched out from the HPT disks, where the centres of these smaller disks were at 2.5 mm distance from the centres of HPT-processed disks. The TEM disks were ground to $\sim 50 \mu \mathrm{m}$ and then ion-milled using a Gatan plasma ion polisher. The average grain sizes of HPT-processed samples were determined from TEM images using the modified line intercept method [16], and the grain size $d$ was taken as $d=1.455 \bar{L}$, where $\bar{L}$ is the average line intercept $[17,18]$. High resolution high-angle annular dark-field scanning transmission electron microscopy (HAADF-STEM) images were performed on a FEI Titan $\mathrm{G}^{2} 60-300$ ChemiSTEM, equipped with a Cs probe corrector and a Super-X EDS with four windowless silicon-drift detectors and operated at $300 \mathrm{kV}$. In order to analyze the coarser constituent phases, X-ray diffraction (XRD) was conducted on the HPT- 
processed samples before and after ageing treatment. The crystallite sizes and microstrains of the Mg-rich matrix phase in the HPT-processed samples were estimated using XRD line broadening analysis with the aid of the Material Analysis Using Diffraction (MAUD) software [18-20]. Detailed information on this analysis was described before in Refs. $[18,21]$. The dislocation density $\rho$ was deduced from the measured microstrains $\left\langle\varepsilon^{2}\right\rangle^{1 / 2}[15,18,22]$ :

$$
\rho=\frac{2 \sqrt{3}\left\langle\varepsilon^{2}\right\rangle^{1 / 2}}{D_{c} b}
$$

where $b$ is the Burgers vector length and $D_{c}$ is the crystallite size.

\section{Results and analysis}

\subsection{Age hardening response}

The hardness of the Mg-8.2Gd-3.8Y-1.0Zn-0.4Zr (wt.\%) alloy after HPT is 126 HV, and Fig. 1 shows the age-hardening curves of the HPT-processed alloy during isothermal ageing at $90{ }^{\circ} \mathrm{C}, 120{ }^{\circ} \mathrm{C}, 150{ }^{\circ} \mathrm{C}$ and $200{ }^{\circ} \mathrm{C}$. These data reveal that artificial ageing at $90{ }^{\circ} \mathrm{C}$ for up to $18 \mathrm{~h}$ leads to a gradual slight increase in hardness, and hardness decreases on continued ageing. During the initial stage of ageing at $120^{\circ} \mathrm{C}$, the hardness gradually increases and a maximum value of $\sim 145 \mathrm{HV}$ is achieved after ageing for $\sim 12$ h. The hardness decreases slightly until ageing for $18 \mathrm{~h}$, and then drops rapidly to $\sim 129$ $\mathrm{HV}$ after ageing for $24 \mathrm{~h}$. When the ageing temperature is increased to $150{ }^{\circ} \mathrm{C}$ and 200 ${ }^{\circ} \mathrm{C}$, the peak hardness reaches $\sim 142 \mathrm{HV}$ and $\sim 141 \mathrm{HV}$ after $6 \mathrm{~h}$ and $3 \mathrm{~h}$, respectively, i.e. the age-hardening progress is accelerated, while peak hardness is reduced. Compared with the age-hardening behavior of the same Mg-8.2Gd-3.8Y-1.0Zn-0.4Zr (wt.\%) alloy processed by conventional extrusion or rolling [4, 23, 24], the present 
HPT-processed alloy shows an accelerated hardening response with a much higher peak hardness obtained at a lower ageing temperature.

\subsection{Variation in electrical conductivity}

Fig. 2 shows the relative change of electrical conductivity, $\left(g-g_{0}\right) / g_{0}$, for the HPTprocessed sample subjected to ageing treatment at $120{ }^{\circ} \mathrm{C}$ for up to $24 \mathrm{~h}$, in which $g_{0}$ is the electrical conductivity of the initial HPT-processed sample (3.27 MS / m), and $g$ represents the electrical conductivity of the aged sample. During the initial $5 \mathrm{~h}$, the electrical conductivity increases rapidly, and subsequently increases at a lower rate until $\sim 18 \mathrm{~h}$, but after $20 \mathrm{~h}$ it accelerates again. It is noteworthy that in comparison with the initial HPT-processed sample (without ageing) the electrical conductivity is increased by $13.7 \%$ after ageing at $120^{\circ} \mathrm{C}$ for $24 \mathrm{~h}$.

\subsection{Microstructure}

Fig. 3(a)-(c) show the TEM images of the HPT-processed alloy before ageing treatment. At this stage the average grain size is about $48 \mathrm{~nm}$, and the corresponding selected area electron diffraction (SAED) pattern shows a number of rings from the $\mathrm{Mg}$ matrix, which confirms the presence of large amount of high angle GBs in the nanostructured Mg alloy. Fig. 3(d)-(i) show the high-angle annular dark-field scanning transmission electron microscopy (HAADF-STEM) image and elemental mappings of HPT-processed sample prior to ageing treatment. This reveals that alloying atoms are distributed homogeneously in the Mg-rich matrix phase.

Fig. 4 shows the TEM microstructure of HPT-processed sample aged at $120{ }^{\circ} \mathrm{C}$ for 
12 h. As shown in Fig. 4(a)-(c), nano-sized grains with high-angle misorientations are retained after this ageing treatment, and some inhomogeneous diffraction contrast caused by a high density of dislocations still exist in grain interiors, further suggesting a good resistance against recovery by rearrangement of dislocations of the HPTdeformed sample. The HAADF-STEM images in Fig. 4(d) and (e), and elemental mappings in Fig. 4(f)-(j) show that after ageing at $120{ }^{\circ} \mathrm{C}$ for $12 \mathrm{~h}$ solute segregation is generated. These solute enriched areas contain both Zn and RE atoms (see Fig. 4(g)(i)), and they are mainly located along GBs as demonstrated by the corresponding atomic-resolution HAADF-STEM image in Fig. 4(e). The peak hardening of the HPTprocessed alloy at $120{ }^{\circ} \mathrm{C}$ is considered to be mainly attributed to the dense nanoscale solute segregation. It also explains why the conductivity increases significantly during ageing up to this stage: solute atoms are clustering around dislocations and grain boundaries and thus substantial parts of the Mg rich phase have less solute atoms (see Discussion section).

After longer ageing to a total of $24 \mathrm{~h}$ at $120^{\circ} \mathrm{C}$, a similar segregation along GBs still exist as seen from Fig. 5(d)-(g), but the average grain size is increased to $\sim 100 \mathrm{~nm}$ (see Fig. 5(a)-(c)), whilst the hardness has decreased. The atomic-resolution HAADFSTEM image shown in Fig. 5(e) provides further evidence that segregation of alloying elements occurs at GBs. The crystallographic structure remains identical to the $\alpha-\mathrm{Mg}$ matrix. These observations suggest that after ageing for $24 \mathrm{~h}$ the hardening solute segregation is retained, but the material is softened due to grain growth.

Fig. 6 shows that when ageing temperature is increased to $200{ }^{\circ} \mathrm{C}$, the segregation 
regions of $\mathrm{RE}$ and $\mathrm{Zn}$ atoms in the vicinity of the GBs become wider and more densely distributed in comparison with the HPT-processed alloy aged at $120{ }^{\circ} \mathrm{C}$. At this higher temperature, the average grain size increases to $\sim 54 \mathrm{~nm}$ after ageing for $3 \mathrm{~h}$ (see Fig. 6(a) and (b)). After ageing for $6 \mathrm{~h}$ at $200{ }^{\circ} \mathrm{C}$, as shown in Fig. 7(a) and (b), the grain size is further increased and diffraction rings become discontinuous. Due to the presence of crystal defects induced by large strains imparted by HPT, the phase transformation cannot be clearly distinguished in the TEM images. However, Fig.7 (c)(i) provides evidence for the generation of well-defined precipitates with an average size of $\sim 20 \mathrm{~nm}$. As almost no segregation can be observed at this stage of ageing, it is likely that these precipitates have formed from solute segregation near GBs. According to the corresponding HRTEM and FFT images given in Fig. 7(j)-(1), the precipitates are identified to be equilibrium $\beta$ phase $\left(\mathrm{Mg}_{5}(\mathrm{RE}, \mathrm{Zn})\right.$, fcc structure [25]). This $\beta$ $\mathrm{Mg}_{5}(\mathrm{RE}, \mathrm{Zn})$ phase has been reported to precipitate in over-aged Mg-RE alloys [26, 27], and GBs usually are the preferential locations for its formation during ageing treatment [25]. It thus appears that the reduction in hardness on over-ageing is due to the coarsening of the grain structure, the formation of a precipitate that is coarse compared to the solute clusters as well as the inevitable decrease in the total dislocation density (see Section 3.4).

\subsection{XRD analysis}

Fig. 8 shows XRD patterns of our HPT-processed and aged Mg-8.2Gd-3.8Y$1.0 \mathrm{Zn}-0.4 \mathrm{Zr}$ (wt.\%) alloy samples. The section of the XRD patterns between $30^{\circ}$ and $40^{\circ}$ presented in Fig. 8(b) shows that ageing at both $120^{\circ} \mathrm{C}$ and $200{ }^{\circ} \mathrm{C}$ induces a shift 
to larger angle (i.e. smaller lattice parameter) for the $\alpha-\mathrm{Mg}$ diffraction peaks. This indicates that during ageing the decomposition of the HPT-deformed $\alpha-\mathrm{Mg}$ supersaturated solid solution occurs, which is in a good agreement with the TEM observations in section 3.3.

The crystallite size, microstrain, dislocation density and lattice constants' ratio $c / a$ of our HPT-processed Mg-Gd-Y-Zn-Zr alloy at different ageing states as obtained from the XRD line broadening analysis are summarized in Table 1. In agreement with grain size growth during ageing as observed by TEM, the crystallite sizes estimated by XRD analysis also increase with ageing, however the crystallite size is smaller than the grain size [18]. The dislocation density of HPT-processed sample is slightly reduced after ageing at $120{ }^{\circ} \mathrm{C}$ for $12 \mathrm{~h}$. When ageing time is prolonged to $24 \mathrm{~h}$, a dramatic decrease in dislocation density and an increase in crystallite size occur, which coincide with softening. The trends in evolutions of crystallite size, microstrain and dislocation density during ageing at $200{ }^{\circ} \mathrm{C}$ are similar with the alloy aged at $120{ }^{\circ} \mathrm{C}$. In addition, the lattice constant $c / a$ of the HPT-processed alloy is increased with increasing ageing temperature and holding time indicating that crystal lattice distortion gradually recovers as the concentrations of the solute elements dissolved in $\alpha-\mathrm{Mg}$ matrix reduce.

\section{Discussion}

\subsection{Segregation in nanostructured Mg-RE alloy processed by HPT}

The ageing response of the present nanostructured $\mathrm{Mg}-\mathrm{RE}$ alloy is significantly different from that of conventional coarse-grained $\mathrm{Mg}$ alloys. In our previous research on ageing behavior of $\mathrm{Mg}-8.2 \mathrm{Gd}-3.8 \mathrm{Y}-1.0 \mathrm{Zn}-0.4 \mathrm{Zr}$ (wt.\%) alloy samples with coarse 
microstructure aged at both $200{ }^{\circ} \mathrm{C}$ and $225^{\circ} \mathrm{C}$, the precipitations sequence is the well established one:

Supersaturated solid solution (SSSS) $\rightarrow \beta^{\prime \prime}\left(\mathrm{D}_{19}\right) \rightarrow \beta^{\prime}(\mathrm{bco}) \rightarrow \beta(\mathrm{fcc})$ [25].

The $\beta^{\prime}$ metastable phase is regarded as the main age hardening phase in conventional thermo-mechanically processed Mg-Gd-Y-Zn-Zr alloys [4, 23, 24]. The present results show that when the grain size of $\mathrm{Mg}-\mathrm{Gd}-\mathrm{Y}-\mathrm{Zn}-\mathrm{Zr}$ is refined to nanoscale, solute clusters at GBs are generated in the peak-ageing stage at both $120^{\circ} \mathrm{C}$ and $200{ }^{\circ} \mathrm{C}$, and the precipitation sequence is changed: no $\beta^{\prime \prime}$ or $\beta^{\prime}$ metastable precipitates form during ageing treatment, and formation of stable $\beta$ phase precipitates occurs without any distinct metastable precursor phase. A similar absence of a distinct metastable precursor phase was also observed in equal-channel angular pressed $\mathrm{Al}-1.7 \mathrm{Cu}$ (at.\%) during ageing at $100^{\circ} \mathrm{C}$ for $24 \mathrm{~h}$. In that case, the nucleation of the equilibrium $\theta$ phase at GBs occurred and the precursor metastable $\theta^{\prime \prime}$ and $\theta^{\prime}$ phases were not observed [28], whilst no evidence for segregations at the grain boundaries was reported. In another report, during ageing of $\mathrm{HPT}-$ deformed $\mathrm{Al}-1 \mathrm{Mg}-4 \mathrm{Cu}(\mathrm{wt} . \%)$ alloy at $150^{\circ} \mathrm{C}$ for two days, no semi-coherent $\mathrm{S}$ or $\mathrm{S}^{\prime}$ precipitates were detected, and instead the $\mathrm{Cu}-\mathrm{Mg}$ clusters were speculated to dominate the strengthening [29].

This phenomenon is also supported by Fig. 2, which indicates the conductivity initially, up to about 3 to $4 \mathrm{~h}$, increases linearly with time. It is clear that removal of solute from the Mg-rich phase is the main process for increase in conductivity and some of this removal of solute proceeds via enrichment at the grain boundary, see Figs. 4 and 5. In other works it has been shown that if solute atoms are mobile they also segregate 
to dislocations, e.g. [18, 30-33]. If segregation to planar defects, e.g. GBs, was the main process for removing solute from $\mathrm{Mg}$-rich phase then there should be a root time dependency of resistivity and if diffusion to linear defects, e.g. dislocations, was the main process for this then the conductivity should increase linearly with time in this initial stage. Thus the observed initial linear increase in Fig. 2 indicates that at least in the first stage (up to about 3 to $4 \mathrm{~h}$ ) diffusion of solute atoms towards line defects is the main process involved. Both segregation at planar defects and linear defects have been implicated in strengthening of a range of alloys [18, 21, 29, 34, 35].

There are two major factors responsible for solute segregation. One factor is likely to be a combination of high solubility and large atomic size difference between RE and $\mathrm{Mg}$ atoms. Two classical models (Langmuir-McClean [36] and Cahn-Lücke-Stüwe [37]) have been used to predict the tendency of solute elements to segregate at GBs, demonstrating that due to elastic strain energy induced by higher size mismatch, the driving force for RE elements to segregate to GBs in Mg alloys is greater than that for more common alloying elements such as $\mathrm{Zn}$ and $\mathrm{Al}$ [37]. For our present $\mathrm{Mg}-\mathrm{Gd}-\mathrm{Y}-\mathrm{Zn}$ alloy it is relevant to note that the atomic radius of the $\mathrm{RE}$ atoms ( $\mathrm{Gd}$ and $\mathrm{Y}$ ) is larger than that of $\mathrm{Mg}$, whereas the atomic radius of transition element $\mathrm{Zn}$ is smaller. Thus the presence of a $\mathrm{RE}$ atom in the $\mathrm{Mg}$-rich phase leads to a positive misfit and a compression strain, while the presence of a $\mathrm{Zn}$ atom causes a negative misfit and an extension strain $[27,38]$. It thus is expected that $\mathrm{RE}$ and $\mathrm{Zn}$ atoms in the Mg-rich solid solution have a propensity to co-segregate at defect sites to minimize the elastic strain. The other factor influencing solute segregation is fast solute diffusion. In SPD processed alloys, the high 
density of defects (GBs, dislocations and vacancies) reduces energy barriers for diffusion. For nanostructured alloys, a large volume fraction of GBs could also provide shorter diffusion pathways compared to coarse grains to enhance thermally activated diffusion rates $[39,40]$ even at a relative low temperature. This means that at $120{ }^{\circ} \mathrm{C}$ the atomic mobility of solutes is high enough to allow most of them to transport from the grain interiors to the GBs within the time needed to reach peak hardness, thus facilitating the formation of segregation regions. The extent of solute segregation is governed by the ageing temperature, which influences both diffusion coefficient and solid solubility in the $\alpha-\mathrm{Mg}$ matrix. After ageing at $200{ }^{\circ} \mathrm{C}$ for $6 \mathrm{~h}$, equilibrium $\beta$ phase precipitates (Fig. 7) are formed through the consumption of alloying elements that had segregated at GBs. It has been reported that the composition of the semi-coherent metastable $\beta^{\prime}$ phase is $\mathrm{Mg}_{7} \mathrm{RE}$ and non-coherent equilibrium $\beta$ phase is $\mathrm{Mg}_{5} \mathrm{RE}$ [27], i.e. the atomic ratio of $\mathrm{RE}$ elements of $\beta$ phase is higher than that of $\beta^{\prime}$ phase. This indicates that the temperature of $200{ }^{\circ} \mathrm{C}$ is high enough to overcome the nucleation barrier necessary for formation of the $\beta$ phase, and also enhance atomic mobility, thereby an accumulation of sufficient solutes in the proximity of interface may favor rapid growth and coarsening of $\beta$ phase.

\subsection{Hardening mechanisms}

As shown in Fig. 1, the optimal ageing condition for hardening is $12 \mathrm{~h}$ at $120^{\circ} \mathrm{C}$. The peak hardness of HPT-deformed Mg-8.2Gd-3.8Y-1.0Zn-0.4Zr (wt.\%) alloys after this optimized ageing treatment $(145 \mathrm{HV})$ is substantially higher than that of the coarse grained counterparts after hot extrusion and rolling followed by ageing [4, 23, 24]. 
In this section we will construct a model for hardening that can explain the very high hardness as well as general ageing behaviour trends. The model considers five main factors which are thought to contribute to hardness: dislocations, GBs, solid solution, nanoscale segregation, and precipitates.

The relationship between hardness $H V$ and yield strength $\sigma_{y}$ can be approximated by the equation:

$$
H V=C \sigma_{y}
$$

where the unit of hardness is $\mathrm{HV}$, and $C$ is a constant about 0.3 [41].

The contribution of grain boundary hardening and dislocation hardening can be assessed by existing models [18, 42].

For the GBs hardening, the Hall-Petch relation is applied, and the hardness increment $H V_{G B}$ is calculated as follows:

$$
\Delta H V_{G B}=C \frac{k_{H P}}{d^{1 / 2}}
$$

where $k_{H P}$ is the Hall-Petch constant for Mg polycrytals, which equals $40.7 \mathrm{MPa} \mu \mathrm{m}^{1 / 2}$ [42], $d$ is the grain size (here obtained from our TEM observations).

For dislocation hardening, the hardness increment $H V_{D}$ is generally accepted to be given by the relationship (see e.g. [42] and references therein):

$$
\Delta H V_{D}=C M \alpha_{1} G b \sqrt{\rho}
$$

where $\rho$ is the dislocation density (measured as $3.85 \times 10^{14} \mathrm{~m}^{-2}$, see Table 1 ), $G$ is the shear modulus $(17.7 \mathrm{GPa}), b$ is the length of the Burgers vector taken as $0.3197 \mathrm{~nm}$, and $\alpha_{1}$ is a constant equalling about $0.3[18,42] . M$ is the Taylor factor, and in the present simplified approach (which does not explicitly consider the various 
fundamental slip directions of the HCP lattice) it is taken here as a single constant equaling 2.6 [42].

For solid solution hardening, the hardness increment $\Delta H V_{S S}$ can be estimated using the following formula [43-45]:

$$
\Delta H V_{S S}=C\left(\sum k_{i}^{1 / n} c_{i}\right)^{n}
$$

where $c_{i}$ are the equilibrium concentrations of solute atoms (i.e. $\mathrm{Gd}, \mathrm{Y}$ and $\mathrm{Zn}$ ) in the matrix phase, $n$ is a constant, which for the present elements dissolved in the $\mathrm{Mg}$ rich phase has been shown to be $1 / 2$ [45], and $k_{i}$ are factors related to individual elements taken as $683 \mathrm{MPa}(\text { at.\%) })^{-1 / 2}, 737 \mathrm{MPa}(\text { at.\%) })^{-1 / 2}, 578 \mathrm{MPa}(\text { at.\% })^{-1 / 2}$ for $\mathrm{Gd}, \mathrm{Y}$ and $\mathrm{Zn}$ elements, respectively [45]. The concentrations of solute atoms, $c_{i}$, are taken from the EDS line profile analysis across the segregation in Fig. 4(e). For the HPT-processed sample, this indicates a composition of $1.40 \pm 0.01$ at. $\% \mathrm{Gd}, 1.20 \pm 0.03$ at.\% Y, $0.40 \pm 0.01$ at. $\% \mathrm{Zn}$, while after peak ageing at $120{ }^{\circ} \mathrm{C}$ it reduces to $0.43 \pm 0.01$ at. $\% \mathrm{Gd}$, $0.47 \pm 0.01$ at. $\% \mathrm{Y}$ and $0.10 \pm 0.02$ at. $\% \mathrm{Zn}$.

Considering the strengthening effect due to the interaction of segregated alloying elements and dislocation, an approximation can be made by using the following equation, which has been applied to estimate the strengthening from $\mathrm{Cu}-\mathrm{Mg}$ segregation in Al-Mg-Cu subjected to HPT [18, 21, 29, 46-48]:

$$
\begin{gathered}
\Delta H V_{\text {Seg }}=C M \Delta \tau_{\text {Seg }} \\
\Delta \tau_{S e g}=\frac{\gamma_{S e g}}{b}=\frac{\Delta H_{A-B}}{b^{3}} \times \frac{4}{\sqrt{3}}\left[\frac{2}{3}\left(y_{A}+y_{B}\right)-\left(\frac{2}{3} x_{B} y_{A}+\frac{2}{3} x_{A} y_{B}+2 x_{A} x_{B}\right)\right]
\end{gathered}
$$

where $\gamma_{S e g}$ is the change in energy per unit area on slip planes, $\Delta H_{A-B}$ is the enthalpy of the nearest neighbour bond, $y_{A}$ and $y_{B}$ represent the amounts of A atoms 
and $\mathrm{B}$ atoms in the co-segregation, whereas $x_{A}$ and $x_{B}$ stand for the amounts of $\mathrm{A}$ atom and $\mathrm{B}$ atoms in the Mg-rich phase. This model of strengthening is based on the additional work required for movement of dislocations due to the presence of solute segregation and clustering $[46,47]$, which is related to the interaction energy between the solute atoms and GBs $[18,21]$. In the case of strengthening of a polycrystals due to solute segregation, application of stress causes dislocations to be activated, move along slip planes to GBs, and cause stress concentrations. When the stress concentration is large enough, a dislocation at the grain boundary in the neighboring grain very close to the boundary may be activated. Thus the cluster/ordering bonds between solute located at or near the grain boundaries are cut by the moving dislocations and the yield strength is increased due to the additional work required to achieve the increase in free energy related to disruption of these near-neighbor bond between solute atoms. As Gd and Y have similar atomic size and valence structure, whilst the mix enthalpy change of Gd$\mathrm{Zn}$ is $31 \mathrm{~kJ} / \mathrm{mol}$ which is relatively close to that of $\mathrm{Y}-\mathrm{Zn}(29 \mathrm{~kJ} / \mathrm{mol})$ [49], we simplify the evaluation of the $\Delta H V_{\text {seg }}$ as follows: the total content of $\mathrm{RE}$ atoms (including $\mathrm{Gd}$ and $\mathrm{Y}$ ) is regarded as A atoms, and the enthalpy change is approximated as $30 \mathrm{~kJ} / \mathrm{mol}$. EDS analysis shows that after peak ageing at $120{ }^{\circ} \mathrm{C}$ the amount of $\mathrm{RE}$ and $\mathrm{Zn}$ atoms in clusters are about $1.72 \pm 0.03$ at. $\%$ (i.e. 0.70 at. $\% \mathrm{Gd}$ and 1.02 at.\% Y) and $0.38 \pm 0.02$ at. $\%$, and in the matrix the compositions are about $0.90 \pm 0.02$ at. $\%$ (i.e. 0.43 at. $\% \mathrm{Gd}$ and 0.47 at. $\%$ Y) and $0.10 \pm 0.02$ at.\%. Using these data and approximations, Eqs.(9) and (10) provide $\Delta H V_{\text {Seg }}=29.5 \mathrm{HV}$ for the peak aged state. A similar assessment (see supplementary material) for the sample aged at $120{ }^{\circ} \mathrm{C}$ for $24 \mathrm{~h}$ (i.e. over aged) then 
provides $\Delta H V_{\text {Seg }}=38.2 \mathrm{HV}$ and for the sample aged at $200{ }^{\circ} \mathrm{C}$ for $3 \mathrm{~h}$ we find $\Delta$ $H V_{\text {Seg }}=32.2 \mathrm{HV}$. For the sample over aged at $200^{\circ} \mathrm{C}$ for $6 \mathrm{~h}$, the amount of RE and $\mathrm{Zn}$ atoms in the matrix are about $0.38 \pm 0.03$ at.\% (i.e. 0.23 at. $\% \mathrm{Gd}$ and 0.15 at. $\% \mathrm{Y}$ ) and $0.01 \pm 0.005$ at. $\%$ respectively, but most solute segregation are transformed into precipitates. The volume fraction of precipitates is obtained from multiple TEM images (see Fig.7), analyzed using Image $\mathrm{J}$ software, which provides $12 \%$. (Here we apply the stereological concept [50] that in a randomly obtained planar section, the area fraction occupied by the particles is equal to the volume fraction of the particles.) Thus, after 6 $\mathrm{h}$ the amount of segregation is reduced by approximately two thirds in comparison with the sample aged at $200{ }^{\circ} \mathrm{C}$ for $3 \mathrm{~h}$, providing $\Delta H V_{\text {Seg }}=12.6 \mathrm{HV}$.

Due to an interaction force stemming from the difference in shear modulus between co-clusters and $\alpha-\mathrm{Mg}$ matrix for the compatible deformation, also modulus hardening $\triangle H V_{M}$ occurs, which can be calculated through a simplified treatment, which has been adopted in a range of works [18, 21, 46-48]:

$$
\Delta H V_{M}=C M \frac{\Delta \mu}{4 \pi \sqrt{2}} f_{S e g}^{1 / 2}
$$

where $\Delta \mu$ is difference in shear moduli between co-segregation $\left(\mu_{S e g}\right)$ and $\mathrm{Mg}$ matrix $\left(\mu_{M g}\right)$. The shear modulus of co-segregation $\left(\mu_{S e g}\right)$ in our alloy is approximated as a weighted average of the modulus of the individual pure substances, i.e.:

$$
\mu_{S e g}=x_{M g} \mu_{M g}+x_{G d} \mu_{G d}+x_{Y} \mu_{Y}+x_{Z n} \mu_{Z n}
$$

where $\mu_{M g}, \mu_{G d}, \mu_{Y}$ and $\mu_{Z n}$ are the shear moduli of $\mathrm{Mg}(17.7 \mathrm{GPa}), \mathrm{Gd}(22.3 \mathrm{GPa})$, $\mathrm{Y}(25.8 \mathrm{GPa}), \mathrm{Zn}(39.5 \mathrm{GPa})[42,51,52]$, and $x_{M g}, x_{G d}, x_{Y}$ and $x_{Z n}$ represent the fractions of the corresponding atoms in the segregation. The $f_{\text {Seg }}$ is the average 
fraction of co-segregation of RE and $\mathrm{Zn}$ atoms, which is again obtained from HAADFSTEM images as $12 \%, 18 \%, 20 \%$ and $7 \%$ respectively for the samples aged at $120{ }^{\circ} \mathrm{C}$ for $12 \mathrm{~h}, 120^{\circ} \mathrm{C}$ for $24 \mathrm{~h}, 200{ }^{\circ} \mathrm{C}$ for $3 \mathrm{~h}$ and $200{ }^{\circ} \mathrm{C}$ for $6 \mathrm{~h}$. This provides $\Delta H V_{M}$ as $5 \mathrm{HV}, 6 \mathrm{HV}, 6 \mathrm{HV}$ and $2.6 \mathrm{HV}$, respectively, for the four conditions. Therefore, the hardening resulting from shear modulus difference for the present samples is calculated to be around $\sim 15 \%$ of $\Delta H V_{S e g}$, i.e. this ratio is close to the result from Ref. [18].

To assess the precipitation hardening in the over-aged sample it is assumed that the dislocations by-pass these obstacles rather than cut them, which has been demonstrated to be reasonable for precipitate strengthening in $\mathrm{Mg}-\mathrm{Zn}$ alloys both in the peak-aged and over-aged conditions [53]. Thus we adopt the Orowan-Ashby equation $[54,55]:$

$$
\Delta H V_{\text {Orowan }}=C \frac{0.13 G b}{\lambda} \ln \frac{d_{p}}{2 b}
$$

where $d_{p}$ is the mean diameter of the particles, and $\lambda$ is the average planar inter-particle spacing. In the present samples, the precipitates are only detected after over ageing at $200{ }^{\circ} \mathrm{C}$. Based on the TEM work on these samples in Fig. $7, d_{p}$ is taken as $\sim 7 \mathrm{~nm}$ and $\lambda$ is taken as $\sim 12 \mathrm{~nm}$, providing $\Delta H V_{\text {orowan }}=43.9 \mathrm{HV}$.

The total hardness after ageing can be expressed as a linear summation of all the contributions assessed above [18]:

$$
H V=H V_{0}+\Delta H V_{G B}+\Delta H V_{D}+\Delta H V_{S S}+\Delta H V_{\text {Seg }}+\Delta H V_{M}+\Delta H V_{\text {Orowan }}
$$

in which $H V_{0}$ is the microhardness of pure $\mathrm{Mg}$ in the annealed state before HPT processing, and it has been estimated at $\sim 6 \mathrm{HV}$ [42]. The calculated hardness values for a range of ageing conditions are presented in Fig. 9. These predicted values are 
consistent with the measured values with average deviation 5\%, and correctly predict the increasing and decreasing trends of hardness on ageing and over-ageing. This indicates that the present model can describe final hardening, and also predicts the hardness in the course of the age hardening process of nanostructured $\mathrm{Mg}$ alloys through on a sound physically-based model.

Fig. 9(a) shows a comparison of the contributions of the different hardening mechanisms under different ageing conditions. It is apparent that as compared to the HPT-processed alloy, the solute segregation in the $120{ }^{\circ} \mathrm{C}$ peak-aged sample affords additional hardening amounting to $20 \%$ of the overall hardness (145 HV), and the GB hardening contribution is almost unchanged due to good thermal stability of nanosized grains. On extending the ageing time to $24 \mathrm{~h}$ at $120^{\circ} \mathrm{C}$, although the hardening effect due to solute segregation increases, the sample hardness is reduced as a result of inevitable grain growth and decreasing dislocation density. After over-ageing at $200{ }^{\circ} \mathrm{C}$, nanosized precipitates provide significant hardening whilst hardening due solute segregation decreases. It should be pointed out that the $\beta$ precipitates observed in conventionally processed Mg-RE type alloys [25, 27] nucleated heterogeneously within the grains and at the grain boundaries during ageing, and these precipitates are relatively coarse with sizes in the micrometer range. These relatively coarse precipitates will have a very limited strengthening effect. In contrast, in the present HPT processed and subsequently over-aged sample, dense nanosized precipitates formed from nanosized solute segregation, and they do contribute substantially to the strength. The decrease in hardness on over-ageing is due to grain growth as well as the annihilation and 
rearrangement of dislocations.

To provide an assessment of the relative merits of the hardness achieved in the present work (145 HV) a wide range of publications on HPT-processed Mg alloys has been analysed $[12,13,15,56-72]$ (see supplementary material). To provide a valid comparison approximating the average hardness of the samples, the positions near the half radius of HPT-deformed disks are considered. This assessment shows that the present HPT-processed Mg-Gd-Y-Zn-Zr alloy possesses a significantly higher hardness than other peak-aged conventional $\mathrm{Mg}$ alloys and $\mathrm{Mg}$-RE alloys processed using a wide range of processing conditions. It thus appears that the present combination of alloying, SPD processing and optimised heat treatment produces a record (average) hardness valid for $\mathrm{Mg}$ alloy samples of at least $\sim 30 \mathrm{~mm}^{3}$ (typical volume of the present HPT samples). Following the above analysis of strengthening effects it appears that grain boundary strengthening and segregation/cluster strengthening are the most potent effects which could be used to further improve hardness/strength beyond the present record levels. As optimizing of grain boundary strengthening through SPD processing of as-cast or as-solution treated alloys has already been investigated in many publications (see e.g. $[10,13,15,16,61,73]$ and references therein), it appears unlikely that further improvement is achievable through that route. Hence, especially further optimization of segregation/cluster strengthening is thought to be a promising direction for future research. For instance the ratio between RE and smaller solute elements (e.g. $\mathrm{Zn}$ ), which strongly influences the cluster strengthening, could be further fine-tuned. Also SPD processing of alloys with nanoscale precipitates may provide routes to further 
optimize grain structure and improve stability of the refined grain structure.

\section{Conclusions}

In this work, a nanostructured Mg-8.2Gd-3.8Y-1.0Zn-0.4Zr (wt.\%) alloy produced by solution treatment and subsequent HPT was subjected to ageing treatment with the aim of achieving a combination of grain refinement hardening and age hardening. The age-hardening behavior and phase transformation at different temperatures were investigated systematically, and the conclusions are summarized as follows:

(1) The optimum ageing condition for HPT-processed Mg-Gd-Y-Zn-Zr alloy is found at a temperature of $120^{\circ} \mathrm{C}$, which is considerably lower than that for conventional thermo-mechanically processed Mg alloys. The peak hardness of $145 \mathrm{HV}$ achieved in the present processing is much higher than those of other HPT-deformed conventional $\mathrm{Mg}$ alloys and Mg-RE alloys reported to date.

(2) The nanostructured Mg-Gd-Y-Zn-Zr alloy has significant changes in ageing response as compared to the Mg-RE alloys with coarse microstructure. The main strengthening structure of the peak-aged Mg-Gd-Y-Zn-Zr processed by HPT is solute segregation, rather than the $\beta^{\prime}$ phase precipitates formed in peak-aged $\mathrm{Mg}-\mathrm{RE}$ alloys processed by extrusion / rolling.

(3) The formation of solute segregation located along grain boundaries is attributed to the numerous grain boundaries and abundant dislocations induced by HPT, which facilitates the diffusivity of alloying elements.

(4) The present combination of alloying, SPD processing and optimised heat treatment 
produces a record (average) hardness for Mg alloy samples.

\section{Acknowledgement}

This work was supported by National Natural Science Foundation of China (No. 51571068) and National Key Research and Development Program of China (No. 2016YFB0301102).

\section{References}

[1] B.L. Mordike, T. Ebert, Magnesium: properties-applications potential, Mater. Sci. Eng. A 302 (2001) 37-45.

[2] Y. Kawamura, K. Hayashi, A. Inoue, Rapidly solidified powder metallurgy Mg97Zn1Y2 alloys with excellent tensile yield strength above $600 \mathrm{MPa}$, Mater. Trans. 42 (2001) 1172-1176.

[3] K. Hagihara, A. Kinoshita, Y. Sugino, M. Yamasaki, Y. Kawamura, H.Y. Yasuda, Y. Umakoshi, Effect of long-period stacking ordered phase on mechanical properties of Mg97Zn1Y2 extruded alloy, Acta Mater. 58 (2010) 6282-6293.

[4] C. Xu, M.Y. Zheng, S.W. Xu, K. Wu, E.D. Wang, S. Kamado, G.J. Wang, X.Y. Lv, Microstructure and mechanical properties of Mg-Gd-Y-Zn-Zr alloy sheets processed by extrusion, hot rolling and ageing, Mater. Sci. Eng. A 559 (2013) 844-851.

[5] Y.H. Ali, D. Qiu, B. Jiang, F.S. Pan, M.X. Zhang, Current research progress in grain refinement of cast magnesium alloys: A review article, J. Alloy Compd. 619 (2015) 639-651.

[6] J.S. Zhang, W.B. Zhang, L.P. Bian, W.L. Cheng, X.F. Niu, C.X. Xu, S.J. Wu, Study of $\mathrm{Mg}-\mathrm{Gd}-\mathrm{Zn}-\mathrm{Zr}$ alloys with long period stacking ordered structures, Mater. Sci. Eng. A 585 (2013) 268-276.

[7] V. Jian, R.S. Mishra, R. Verma, E. Essadiqi, Superplasticity and microstructural stability in a $\mathrm{Mg}$ alloy processed by hot rolling and friction stir processing, Scripta Mater. 68 (2013) 447-450.

[8] F.M. Lu, A.B. Ma, J.H. Jiang, D.H. Yang, Y.C. Yuan, L.Y. Zhang, Formation of profuse long period stacking ordered microcells in $\mathrm{Mg}-\mathrm{Gd}-\mathrm{Zn}-\mathrm{Zr}$ alloy during multipass ECAP process, J. Alloy Compd. 601 (2014) 140-145.

[9] R.Z. Valiev, R.K. Islamgaliev, I.V. Alexandrov, Bulk nanostructured materials from severe plastic deformation, Prog. Mater. Sci. 45 (2000) 103-189.

[10] A.P. Zhilyaev, T.G. Langdon, Using high-pressure torsion for metal processing: fundamentals and application, Prog. Mater. Sci. 53 (2008) 893-979.

[11] X. Sauvage, N. Enikeev, R. Valiev, Y. Nasedkina, M. Murashkin, Atomic-scale analysis of the segregation and precipitation mechanisms in a severely deformed AlMg alloy, Acta Mater. 72 (2014) 125-136. 
[12] M. VlČek, J. Č́ížek, O. Melikhova, P. Hruška, I. Procházka, Investigation of precipitation effects in Mg-Tb and Mg-Tb-Nd alloys, Acta Phys. Pol. A 125 (2014) 744-747.

[13] S.V. Dobatkin, L.L. Rokhlin, E.A. Lukyanova, M. YuMurashkin, T.V. Dobatkina, N. Yu Tabachkova, Structure and mechanical properties of the Mg-Y-Gd-Zr alloy after high pressure torsion, Mater. Sci. Eng. A 667 (2016) 217-223.

[14] C. Xu, M.Y. Zheng, K. Wu, E.D. Wang, G.H. Fan, S.W. Xu, S. Kamado, X.D. Liu, G.J. Wang, X.Y. Lv, Effect of cooling rate on the microstructure evolution and mechanical properties of homogenized Mg-Gd-Y-Zn-Zr alloy, Mater. Sci. Eng. A 559 (2013) 364-370.

[15] W.T. Sun, X.G. Qiao, M.Y. Zheng, C. Xu, N. Gao, M.J. Starink, Microstructure and mechanical properties of a nanostructured Mg-8.2Gd-3.8Y-1.0Zn-0.4Zr supersaturated solid solution prepared by high pressure torsion, Mater. Des. 135 (2017) 366-376.

[16] M.J. Starink, X.G. Qiao, J. Zhang, N. Gao, Predicting grain refinement by cold severe plastic deformation in alloys using volume averaged dislocation generation, Acta Mater. 57 (2009) 5796-5811.

[17] A. Thorvaldsen, The intercept method-1. Evaluation of grain shape, Acta Mater. 45 (1997) 587-594.

[18] Y. Chen, N. Gao, G. Sha, S.P. Ringer, M.J. Starink, Microstructural evolution, strengthening and thermal stability of an ultrafine-grained $\mathrm{Al}-\mathrm{Cu}-\mathrm{Mg}$ alloy, Acta Mater. 109 (2016) 202-212.

[19] M. Ferrari, L. Lutterotti, Method for the simultaneous determination of anisotropic residual stresses and texture by X-ray diffraction, J. Appl. Phys. 76 (1994) 7246-7255. [20] L. Lutterotti, S. Gialanella, X-ray diffraction characterization of heavily deformed metallic specimens, Acta Mater. 46 (1998) 101-110.

[21] Y. Chen, N. Gao, G. Sha, S.P. Ringer, M.J. Starink, Strengthening of an Al-Cu-Mg alloy processed by high-pressure torsion due to clusters, defects and defect-cluster complexes, Mater. Sci. Eng. A 627 (2015) 10-20.

[22] G.K. Williamson, R.E. Smallman, Dislocation densities in some annealed and cold-worked metals from measurements on the X-Ray Debye-Scherrer spectrum, Philos. Mag.1 (1956) 34-46.

[23] Y.Q. Chi, M.Y. Zheng, C. Xu, Y.Z. Du, X.G. Qiao, K. Wu, X.D. Liu, G.J. Wang, X.Y. Lv, Effect of ageing treatment on the microstructure, texture and mechanical properties of extruded Mg-8.2Gd-3.8Y-1Zn-0.4Zr (wt\%) alloy, Mater. Sci. Eng. A 565 (2013) 112-117.

[24] C. Xu, M.Y. Zheng, S.W. Xu, K. Wu, E.D. Wang, S. Kamado, G.J. Wang, X.Y. Lv, Ultra high-strength Mg-Gd-Y-Zn-Zr alloy sheets processed by large-strain hot rolling and ageing, Mater. Sci. Eng. A 547 (2012) 93-98.

[25] C. Xu, M.Y. Zheng, K. Wu, E.D. Wang, G.H. Fan, S.W. Xu, S. Kamado, X.D. Liu, G.J. Wang, X.Y. Lv, Effect of ageing treatment on the precipitation behaviour of $\mathrm{Mg}$ Gd-Y-Zn-Zr alloy, J. Alloy Compd. 550 (2013) 50-56.

[26] S.M. He, X.Q. Zeng, L.M. Peng, X. Gao, J.F. Nie, W.J. Ding, Precipitation in a 
Mg-10Gd-3Y-0.4Zr (wt.\%) alloy during isothermal ageing at $250{ }^{\circ} \mathrm{C}$, J. Alloy Compd. 421 (2006) 309-313.

[27] J.F. Nie, Precipitation and hardening in magnesium alloys, Metall. Mater. Trans. A 43A (2012) 3891-3939.

[28] M. Murayama, Z. Horita, K. Hono, Microstructure of two-phase Al-1.7 at\% Cu alloy deformed by equal-channel angular pressing, Acta Mater. 49 ( 2001) 21-29.

[29] J.W. Zhang, N. Gao, M.J. Starink, Al-Mg-Cu based alloys and pure Al processed by high pressure torsion: the influence of alloying additions on strengthening, Mater. Sci. Eng. A 527 (2010) 3472-3479.

[30] K. Hoummada, D. Mangelinck, B. Gault, M. Cabié, Nickel segregation on dislocation loops in implanted silicon, Scr. Mater. 64 (2011) 378-381.

[31] C. Lotharukpong, D. Tweddle, T.L. Martin, M. Wu, C.R.M. Grovenor, M.P. Moody, P.R. Wilshaw, Specimen preparation methods for elemental characterisation of grain boundaries and isolated dislocations in multicrystalline silicon using atom probe tomography, Mater. Charact. 131 (2017) 472-479.

[32] H. Rehman, K. Durst, S. Neumeier, A. Sato, R. Reed, M. Göken, On the temperature dependent strengthening of nickel by transition metal solutes, Acta Mater. 137 (2017) 54-63.

[33] M.I. Pascuet, E. Martínez, G. Monnet, L. Malerba, Solute effects on edge dislocation pinning in complex alpha-Fe alloys, J. Nucl. Mater. 494 (2017) 311-321.

[34] M.M. Abramova, N.A. Enikeev, R.Z. Valiev, A. Etienne, B. Radiguet, Y. Ivanisenko, X. Sauvage, Grain boundary segregation induced strengthening of an ultrafine-grained austenitic stainless steel, Mater. Lett. 136 (2014) 349-352.

[35] Z.Q. Yang, M.F. Chisholm, G. Duscher, X.L. Ma, S.J. Pennycook, Direct observation of dislocation dissociation and Suzuki segregation in a Mg-Zn-Y alloy by aberration-corrected scanning transmission electron microscopy, Acta Mater. 61 (2013) 350-359.

[36] D. McLean, Grain boundaries in metals, Oxford University Press, Oxford, UK, 1957.

[37] J.D. Robson, Effect of rare-earth additions on the texture of wrought magnesium alloys: the role of grain boundary segregation, Metall. Mater. Trans. A 45 (2014) 32053212.

[38] J.D. Robson, S.J. Haigh, B. Davis, D. Griffiths, Grain boundary segregation of rare-earth elements in magnesium alloys, Metall. Mater. Trans. A 47A (2016) 522-530. [39] Y. Amouyal, S.V. Divinski, Y. Estrin, E. Rabkin, Short-circuit diffusion in an ultrafine-grained copper-zirconium alloy produced by equal channel angular pressing, Acta Mater. 55 (2007) 5968-5979.

[40] D. Prokoshkina, L. Klinger, A. Moros, G. Wilde, E. Rabkin, S.V. Divinski, Persistence of ultrafast atomic diffusion paths in recrystallizing ultrafine grained $\mathrm{Ni}$, Scripta Mater. 101 (2015) 91-94.

[41] P. Zhang, S.X. Li, Z.F. Zhang, General relationship between strength and hardness, Mater. Sci. Eng. A 529 (2011) 62-73.

[42] M.J. Starink, X. Cheng, S. Yang, Hardening of pure metals by high-pressure torsion: A physically based model employing volume-averaged defect evolutions, Acta 
Mater. 61 (2013) 183-192.

[43] L.A. Gypen, A. Deruyttere, Multi-component solid solution hardening, J. Mater. Sci. 12 (1977) 1028-1033.

[44] O. Ryen, B. Holmedal, O. Nijs, E. Nes, E. Sjölander, H.-E. Ekström, Strengthening mechanisms in solid solution aluminum alloys, Metall. Mater. Trans. A 37 (2006) 19992006.

[45] L. Gao, R.S. Chen, E.H. Han, Effects of rare-earth elements Gd and Y on the solid solution strengthening of Mg alloys, J. Alloy Compd. 481 (2009) 379-384.

[46] M.J. Starink, S.C. Wang, The thermodynamics of and strengthening due to coclusters: General theory and application to the case of Al-Cu-Mg alloys, Acta Mater. 57 (2009) 2376-2389.

[47] M.J. Starink, L.F. Cao, P.A. Rometsch, A model for the thermodynamics of and strengthening due to co-clusters in Al-Mg-Si-based alloys, Acta Mater. 60 (2012) 41944207.

[48] M.J. Starink, N. Gao, L. Davin, J. Yan, A. Cerezo, Room temperature precipitation in quenched $\mathrm{Al}-\mathrm{Cu}-\mathrm{Mg}$ alloys: a model for the reaction kinetics and yield strength development, Philos. Mag. 85 (2005) 1395-1417.

[49] A. Takeuchi, A. Inoue, Classification of bulk metallic glasses by atomic size difference, heat of mixing and period of constituent elements and its application to characterization of the main alloying element, Mater. Trans. 46 (2005) 2817-2829.

[50] E. Underwood, Quantitative stereology, Addison-Wesley Pub. Co., 1970.

[51] L.L. Rokhlin: Magnesium alloys containing rare earth metals, Taylor and Francis, London, 2003.

[52] M.W. Guinan, D.J. Steinberg, Pressure and temperature derivatives of the isotropic polycrystalline shear modulus for 65 elements, J. Phys. Chem. Solids 35 (1974) 15011512.

[53] J.M. Rosalie, H. Somekawa, A. Singh, T. Mukai, The effect of size and distribution of rod-shaped precipitates on the strength and ductility of a Mg-Zn alloy, Mater. Sci. Eng. A 539 (2012) 230-237.

[54] G.E. Dieter, Mechanical metallurgy, third ed., Mc-Graw-Hill, New York, 1986, pp. 212-220.

[55] Z. Zhang, D.L. Chen, Consideration of Orowan strengthening effect in particulatereinforced metal matrix nanocomposites: A model for predicting their yield strength, Scripta Mater. 54 (2006) 1321-1326.

[56] F.Q. Meng, J. M. Rosalie, A. Singh, H. Somekawa, K. Tsuchiya, Ultrafine grain formation in $\mathrm{Mg}-\mathrm{Zn}$ alloy by in situ precipitation during high-pressure torsion, Scripta Mater. 78-79 (2014) 57-60.

[57] L.R.C. Malheiros, R.B. Figueiredo, T.G. Langdon, Grain size and microhardness evolution during annealing of a magnesium alloy processed by high-pressure torsion, J. Mater. Res. Technol. 4 (2015) 14-17.

[58] Y. Huang, R.B. Figueiredo, T. Baudin, A.L. Helbert, F. Brisset, T.G. Langdon, Effect of temperature on the processing of a magnesium alloy by high-pressure torsion, J. Mater. Sci. 47 (2012) 7796-7806. 
[59] Y. Huang, R.B. Figueiredo, T. Baudin, F. Brisset, T.G. Langdon, Evolution of strength and homogeneity in a magnesium AZ31 alloy processed by high-pressure torsion at different temperatures, Adv. Eng. Mater. 14 (2012) 1018-1026.

[60] J. Vrátná, M. Janeček, J. Č́ížek, D.J. Lee, E.Y. Yoon, H.S. Kim, Mechanical properties and microstructure evolution in ultrafinegrained AZ31 alloy processed by severe plastic deformation, J. Mater. Sci. 48 (2013) 4705-4712.

[61] M. Kawasaki, R.B. Figueiredo, Y. Huang, T.G. Langdon, Interpretation of hardness evolution in metals processed by high-pressure torsion, J. Mater. Sci. 49 (2014) 65866596.

[62] M. Kai, Z. Horita, T.G. Langdon, Developing grain refinement and superplasticity in a magnesium alloy processed by high-pressure torsion, Mater. Sci. Eng. A 488 (2008) 117-124.

[63] O.B. Kulyasova, R.K. Islamgaliev, Y.H. Zhao, R.Z. Valiev, Enhancement of the mechanical properties of an $\mathrm{Mg}-\mathrm{Zn}-\mathrm{Ca}$ alloy using high-pressure torsion, Adv. Eng. Mater. 17 (2015) 1738-1741.

[64] H.J. Lee, S.K. Lee, K.H. Jung, G.A. Lee, B. Ahn, M. Kawasaki, T.G. Langdon, Evolution in hardness and texture of a ZK60A magnesium alloy processed by highpressure torsion, Mater. Sci. Eng. A 630 (2015) 90-98.

[65] H.J. Lee, B. Ahn, M. Kawasaki, T.G. Langdon, Evolution in hardness and microstructure of ZK60A magnesium alloy processed by high-pressure torsion J. Mater. Res. Technol. 4 (2015) 18-25.

[66] S.A. Torbati-Sarraf, T.G. Langdon, Properties of a ZK60 magnesium alloy processed by high-pressure torsion, J. Alloy Compd. 613 (2014) 357-363.

[67] R.X. Zheng, T. Bhattacharjee, A. Shibata, T. Sasaki, K. Hono, M. Joshi, N. Tsuji, Simultaneously enhanced strength and ductility of $\mathrm{Mg}-\mathrm{Zn}-\mathrm{Zr}-\mathrm{Ca}$ alloy with fully recrystallized ultrafine grained structures, Scripta Mater. 131 (2017) 1-5.

[68] O.B. Kulyasova, R.K. Islamgaliev, A.R. Kil'mametov, R.Z. Valiev, Superplastic behavior of magnesium-based Mg-10 wt\% Gd alloy after severe plastic deformation by torsion, Phys. Met. Metallogr. 101 (2006) 585-590.

[69] A. Singh, D.A. Basha, H. Somekawa, K. Tsuchiya, Nucleation of recrystallized magnesium grains over quasicrystalline phase during severe plastic deformation of a Mg-Zn-Y alloy at room temperature, Scripta Mater. 134 (2017) 80-84.

[70] R. Kocich, L. Kunčická, P. Král, T.C. Lowe, Texture, deformation twinning and hardening in a newly developed $\mathrm{Mg}-\mathrm{Dy}-\mathrm{Al}-\mathrm{Zn}-\mathrm{Zr}$ alloy processed with high pressure torsion, Mater. Des. 90 (2016) 1092-1099.

[71] L.L. Tang, Y.H. Zhao, N.N. Liang, R.K. Islamgaliev, R.Z. Valiev, Y.T. Zhu, Localized deformation via multiple twinning in a Mg-Gd-Y-Zr alloy processed by highpressure torsion, Mater. Sci. Eng. A 677 (2016) 68-75.

[72] W.T. Sun, C. Xu, X.G. Qiao, M.Y. Zheng, S. Kamado, N. Gao, M.J. Starink, Evolution of microstructure and mechanical properties of an as-cast Mg-8.2Gd-3.8Y$1.0 \mathrm{Zn}-0.4 \mathrm{Zr}$ alloy processed by high pressure torsion, Mater. Sci. Eng. A 700 (2017) 312-320.

[73] M.J. Starink, Dislocation versus grain boundary strengthening in SPD processed 
metals: non-causal relation between grain size and strength of deformed polycrystals, Mater. Sci. Eng. A 705 (2017) 42-45.

Table:

Table 1 the crystallite size, microstrain, dislocation density and lattice axial ratio $c / a$ of HPTprocessed Mg-Gd-Y-Zn-Zr alloy at different ageing states.

\begin{tabular}{ccccc}
\hline Samples & $\begin{array}{c}\text { Crystallite size } \\
D_{c}(\mathrm{~nm})\end{array}$ & $\begin{array}{c}\text { Microstrain } \varepsilon \\
(\%)\end{array}$ & $\begin{array}{c}\text { Dislocation density } \rho \\
\left(\times 10^{14} \mathrm{~m}^{-2}\right)\end{array}$ & $\begin{array}{c}\text { Lattice axial } \\
\text { ratio } c / a\end{array}$ \\
\hline HPT-processed & 45.4 & 0.195 & 4.65 & 1.6125 \\
$120{ }^{\circ} \mathrm{C} / 12 \mathrm{~h}$ & 48.2 & 0.172 & 3.85 & 1.6140 \\
$120{ }^{\circ} \mathrm{C} / 24 \mathrm{~h}$ & 60.4 & 0.163 & 2.92 & 1.6153 \\
$200{ }^{\circ} \mathrm{C} / 3 \mathrm{~h}$ & 52.4 & 0.162 & 3.34 & 1.6149 \\
$200{ }^{\circ} \mathrm{C} / 6 \mathrm{~h}$ & 62.0 & 0.160 & 2.80 & 1.6203 \\
\hline
\end{tabular}




\section{Figures:}

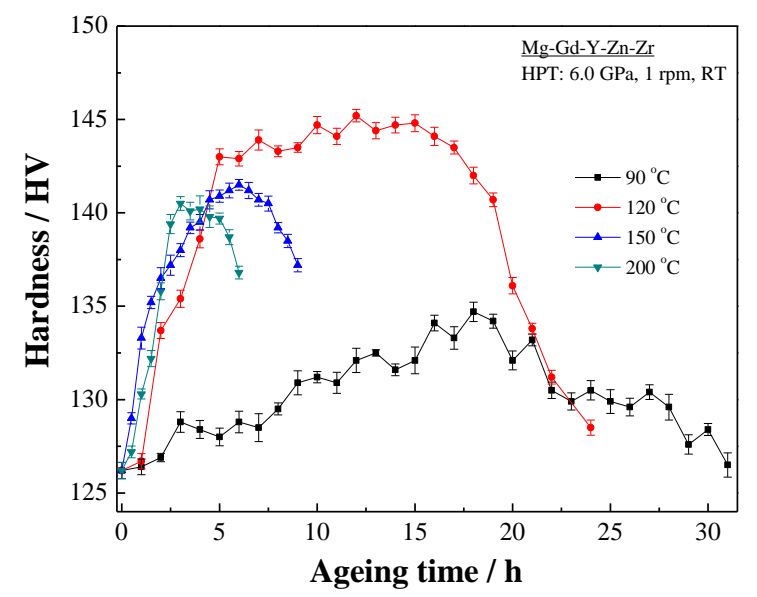

Fig.1 Age-hardening curves of the HPT deformed alloy aged at different temperatures.

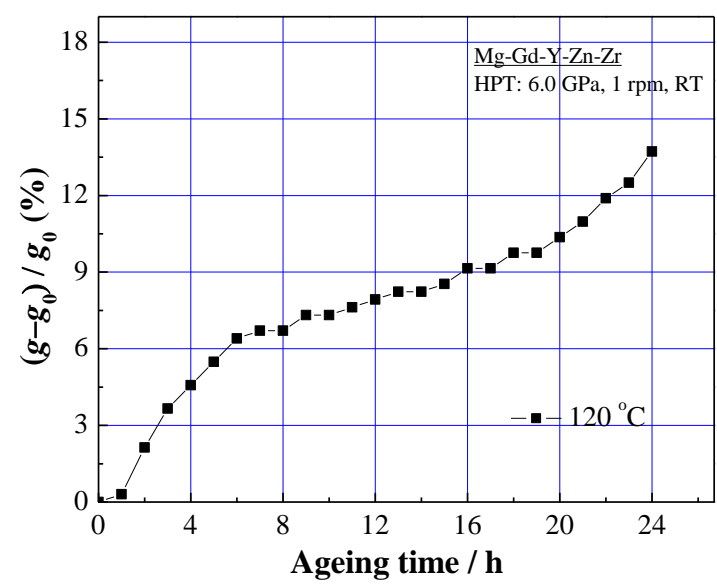

Fig. 2 Relative changes of electrical conductivity $\left(g-g_{0}\right) / g_{0}$ for HPT-processed sample subjected to ageing treatment at $120^{\circ} \mathrm{C}$. 

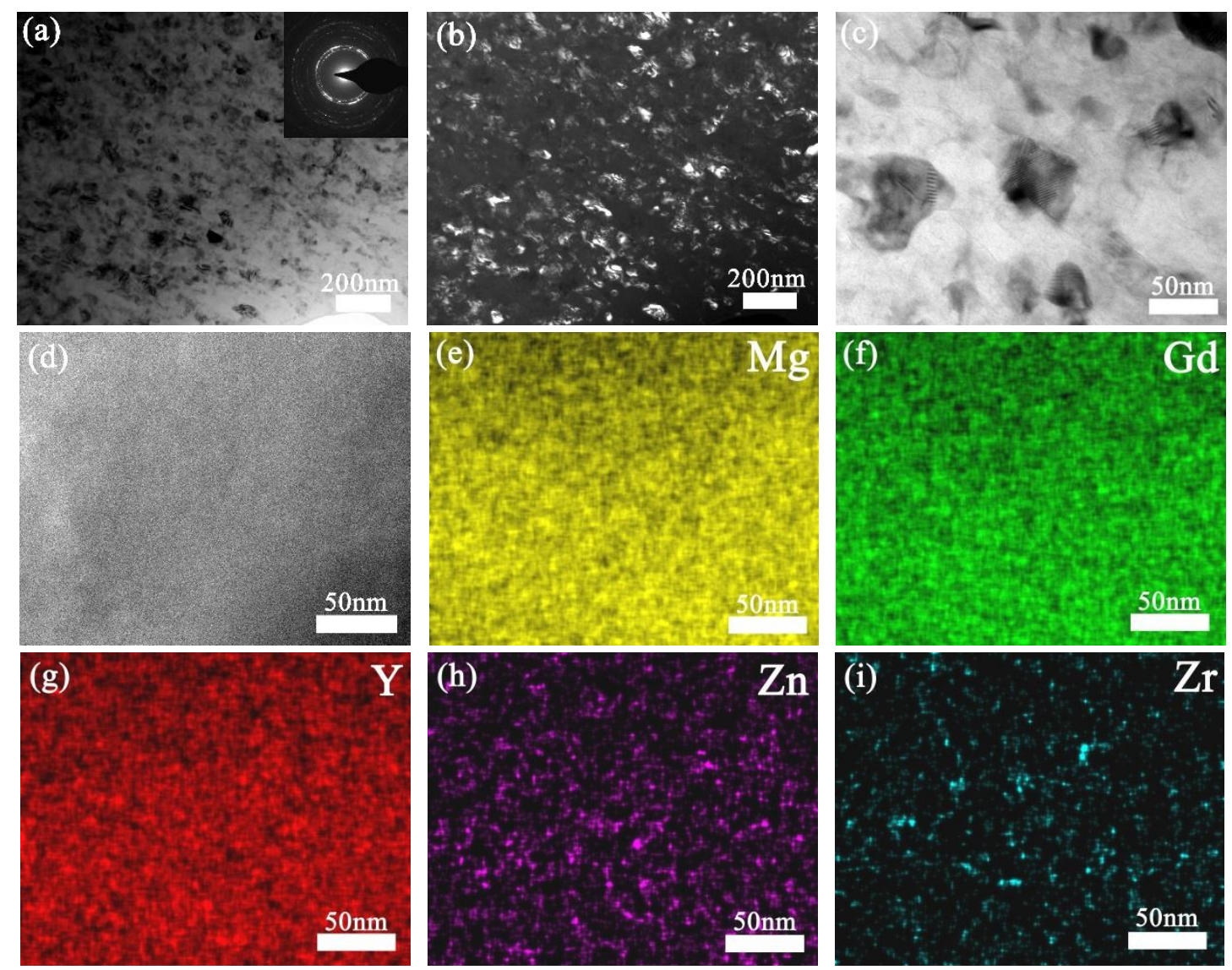

Fig.3 Microstructure of the HPT-processed alloy before ageing treatment: (a) TEM bright-field image and corresponding selected area electron diffraction (SAED) patterns; (b) TEM dark-field image; (c) A high magnification TEM bright-field image; (d) HAADF-STEM image, and elemental mappings: (e) Mg; (f) Gd; (g) Y; (h) Zn and (i) Zr. 

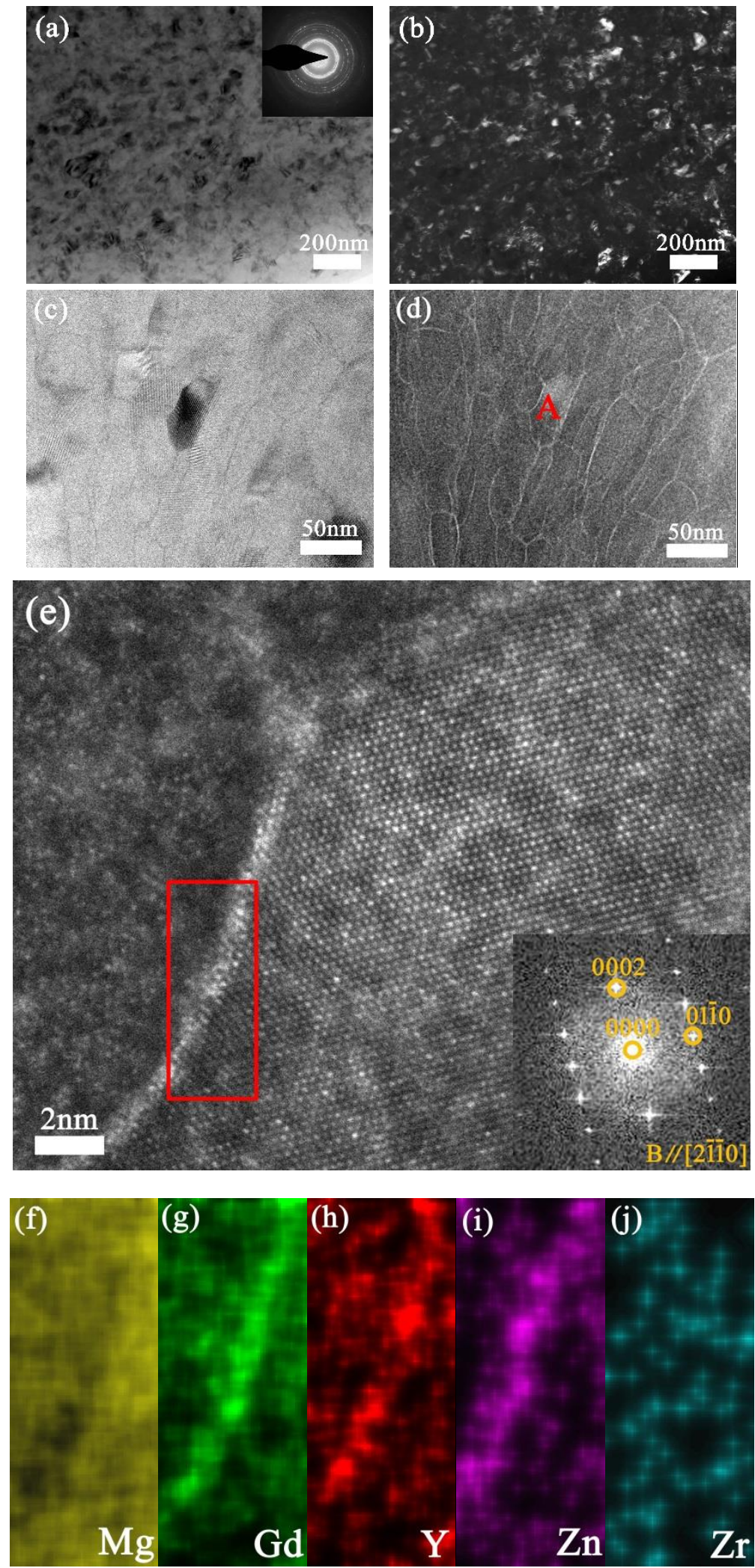

Fig. 4 Microstructure of the HPT-processed sample aged at $120^{\circ} \mathrm{C}$ for $12 \mathrm{~h}$ : (a) TEM bright-field image and corresponding SAED pattern; (b) TEM dark-field image; (c) A high magnification TEM bright-field image; (d) HAADF-STEM image; (e) Atomic-resolution HAADF-STEM image of grain A marked in (d) and corresponding Fast Fourier transform (FFT) image, and elemental mappings of red rectangular region marked in (e): (f) $\mathrm{Mg}$; (g) Gd; (h) Y; (i) Zn; (j) Zr. 

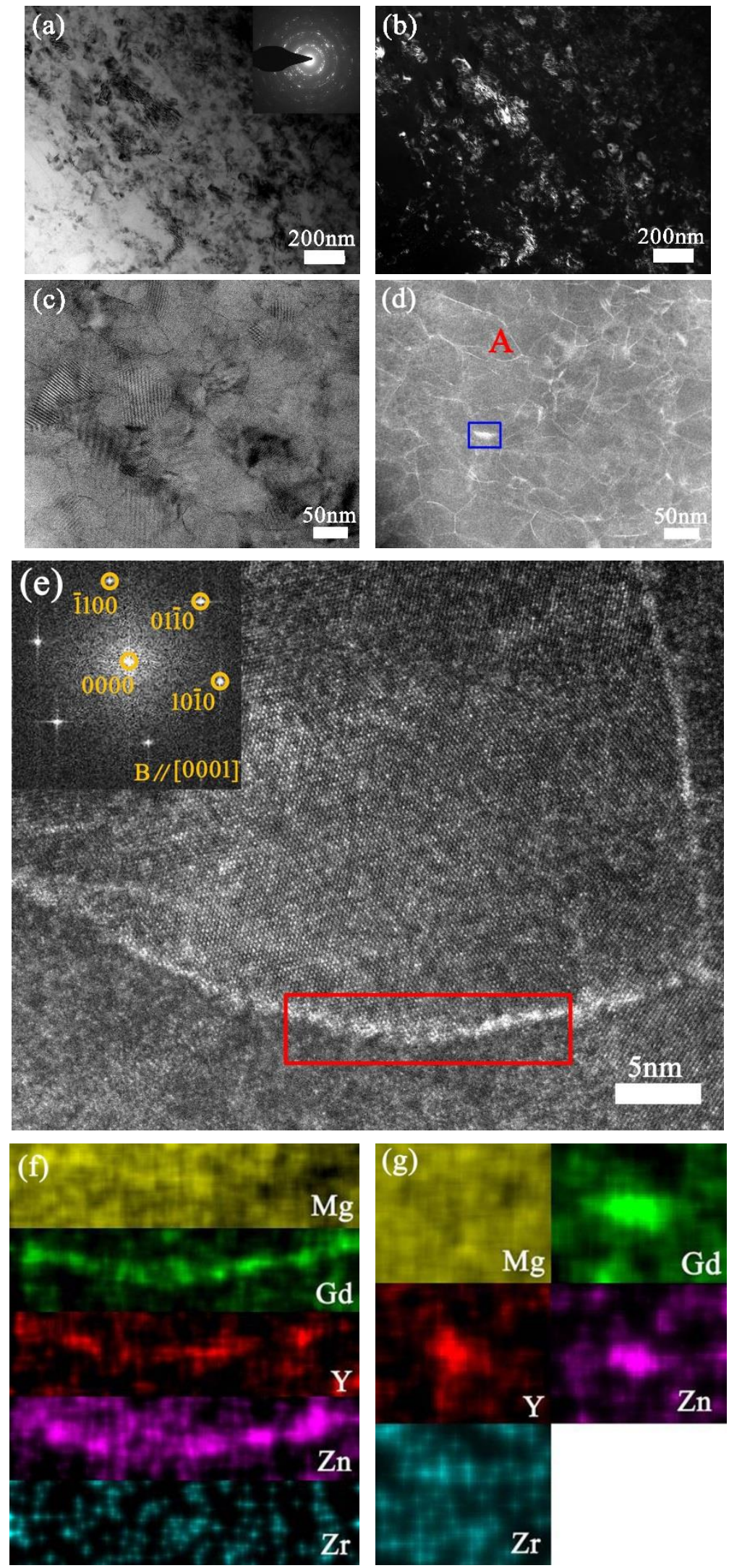

Fig. 5 Microstructure of the HPT-processed sample aged at $120^{\circ} \mathrm{C}$ for $24 \mathrm{~h}$ : (a) TEM bright-field image and corresponding SAED pattern; (b) TEM dark-field image; (c) A high magnification TEM bright-field image; (d) HAADF-STEM image; (e) Atomic-resolution HAADF-STEM image of grain A marked in (d) and corresponding FFT image; (f) Elemental mappings of red 
rectangular region marked in (e); (g) Elemental mappings of blue rectangular region marked in (d). 

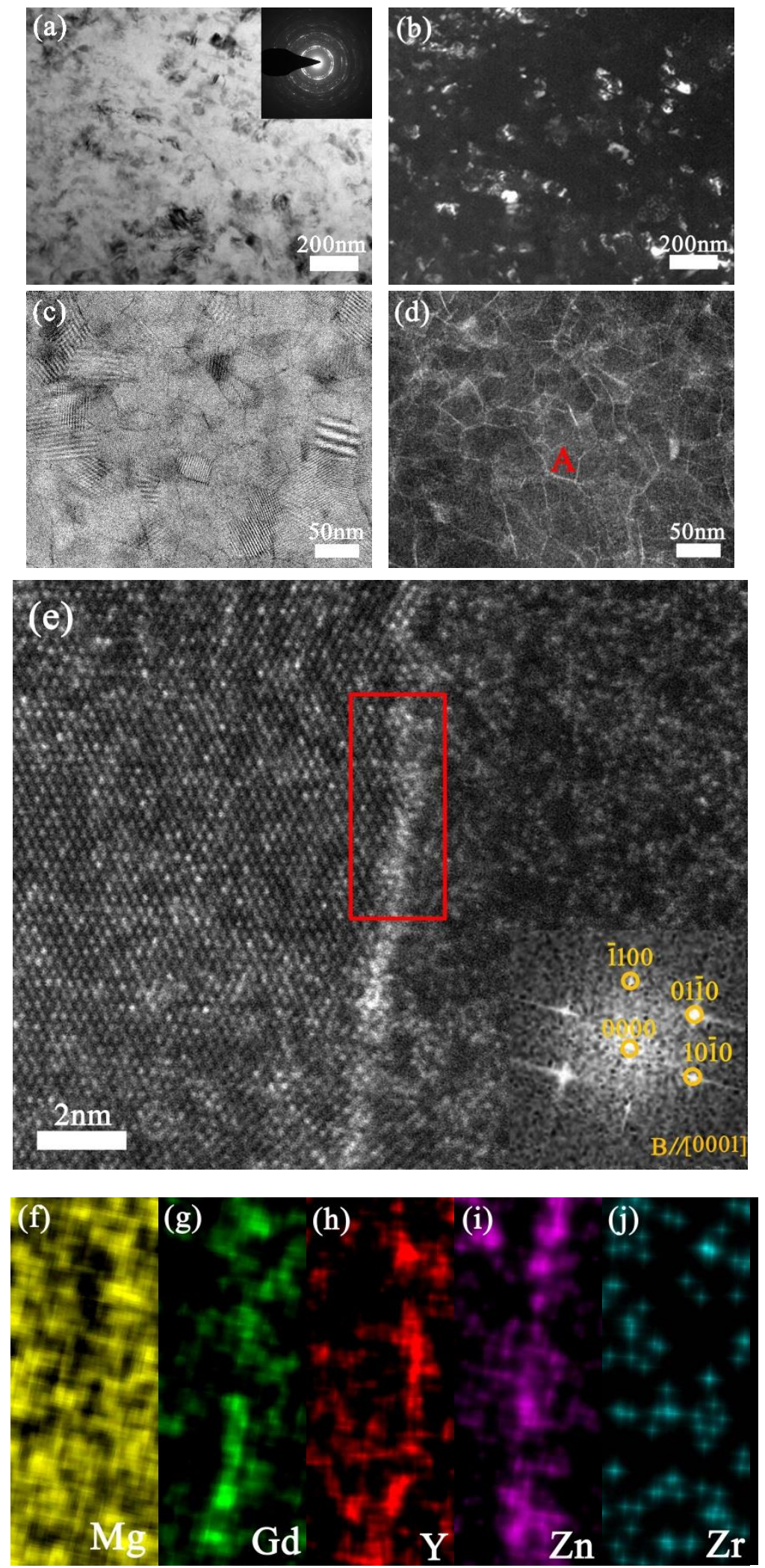

Fig. 6 Microstructure of the HPT-processed sample aged at $200{ }^{\circ} \mathrm{C}$ for $3 \mathrm{~h}$ : (a) TEM bright-field image and corresponding SAED pattern; (b) TEM dark-field micrograph; (c) A high magnification TEM bright-field image; (d) HAADF-STEM image; (e) Atomic- resolution HAADF-STEM image of grain A marked in (d) and corresponding FFT image, and elemental mappings of red rectangular region marked in (e): (f) Mg; (g) Gd; (h) Y; (i) Zn; (j) Zr. 


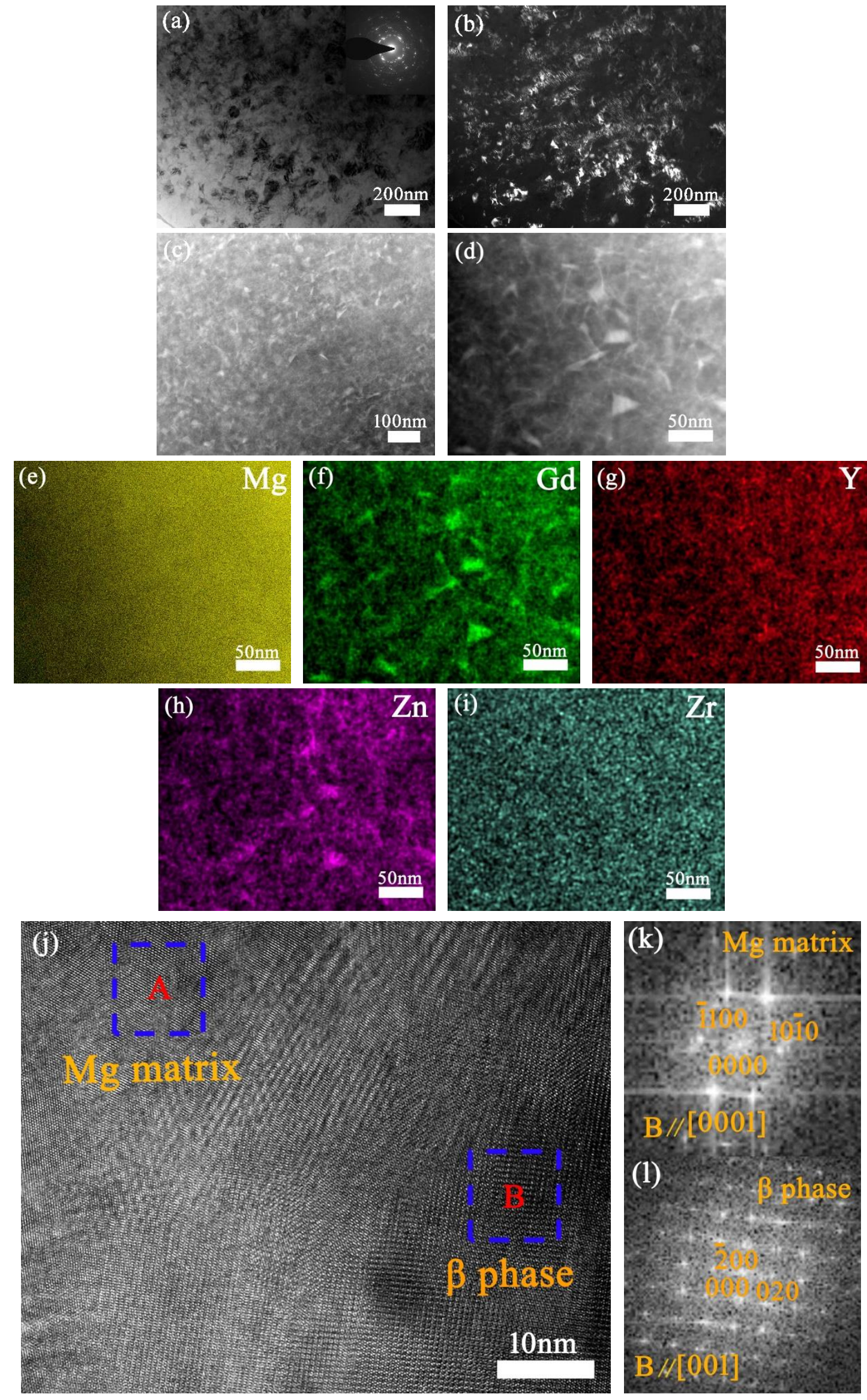

Fig. 7 Microstructure of the HPT-processed sample aged at $200{ }^{\circ} \mathrm{C}$ for $6 \mathrm{~h}$ : (a) TEM bright-field 
image and corresponding SAED pattern; (b) TEM dark-field micrograph; (c) HAADF-STEM image; (d) high magnification of (c); elemental mappings of (c): (e) Mg; (f) Gd; (g) Y; (h) Zn; (i) $\mathrm{Zr}$; (j) HRTEM image; (k) and (l) FFT images of regions in (j) marked by squares A and B respectively. 

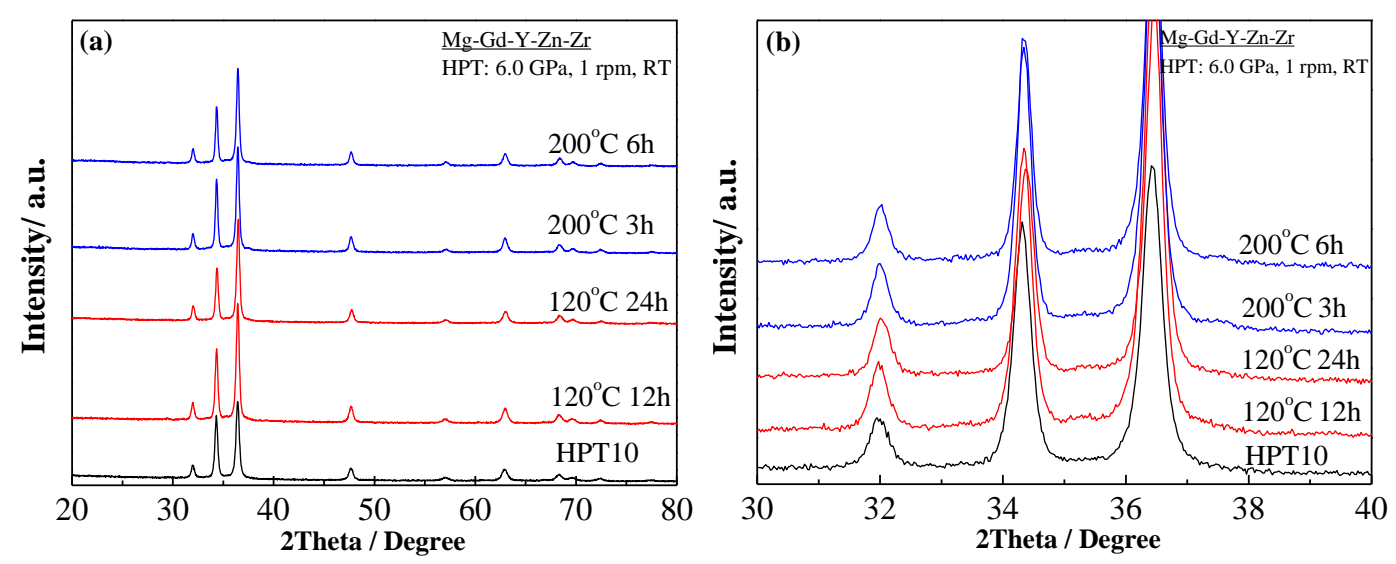

Fig.8 (a) Overview of XRD patterns of the HPT-deformed and aged Mg-Gd-Y-Zn-Zr; (b) enlarged section of the XRD patterns.
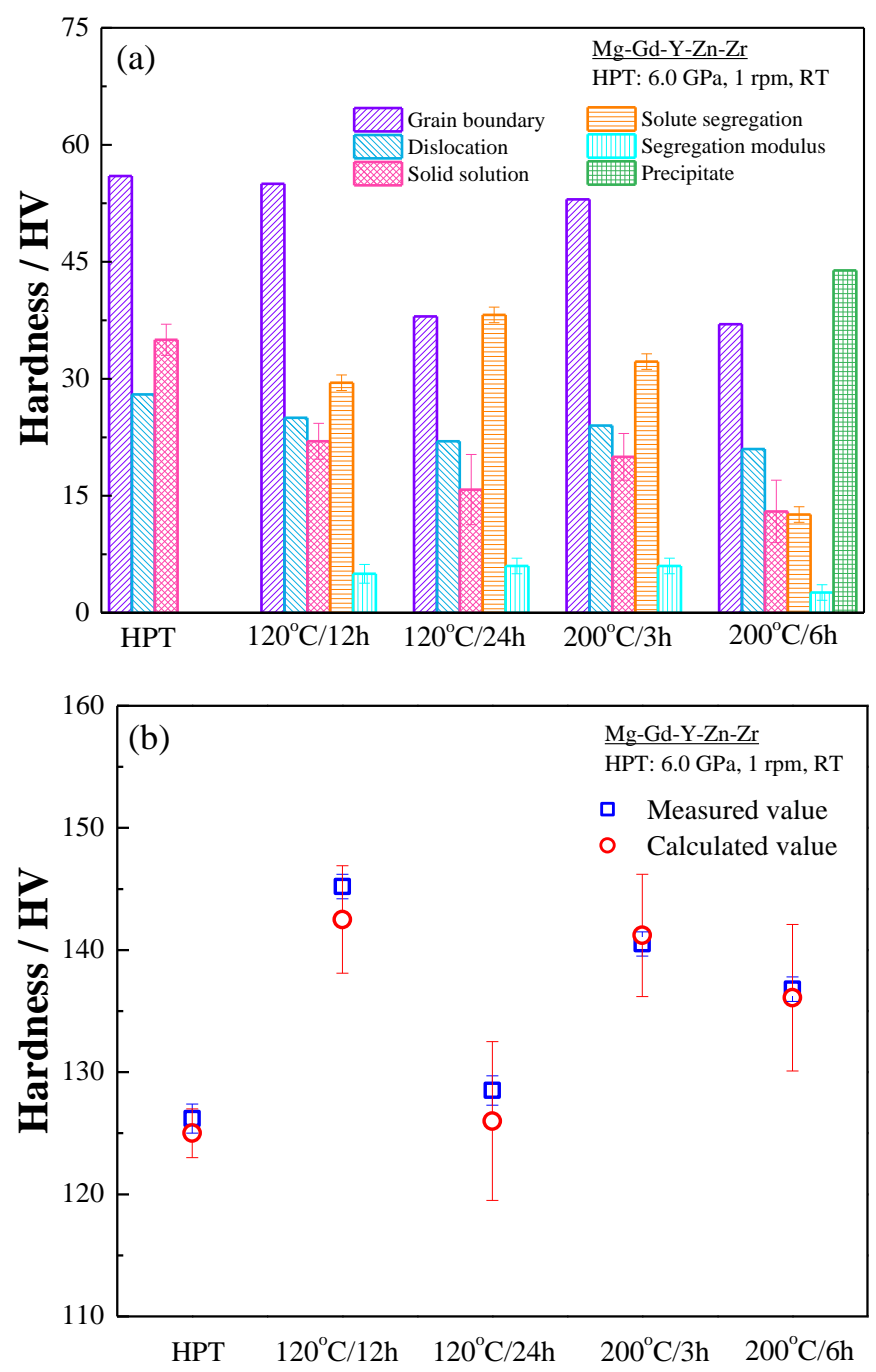

Fig. 9 (a) Contribution of each mechanism to hardness for HPT-processed Mg-Gd-Y-Zn-Zr alloy under different ageing conditions; (b) Comparison between calculated hardness and measured hardness. 


\section{Supplementary material:}

EDS analysis showed that in the $120{ }^{\circ} \mathrm{C}$ for $24 \mathrm{~h}$ aged condition the amount of atoms in clusters is $1.83 \pm 0.02$ at.\% $\mathrm{RE}$ (i.e. 0.75 at.\% $\mathrm{Gd}$ and 1.08 at.\% $\mathrm{Y}$ ) and $0.42 \pm 0.01$ at. $\% \mathrm{Zn}$, and in matrix are about $0.44 \pm 0.04$ at.\% RE (i.e. 0.22 at.\% $\mathrm{Gd}$ and 0.20 at.\% Y) and $0.04 \pm 0.01$ at.\% $\mathrm{Zn}$.) Under the condition of ageing at $200{ }^{\circ} \mathrm{C}$ for $3 \mathrm{~h}$ the amount of $\mathrm{RE}$ and $\mathrm{Zn}$ atoms in clusters approximate $1.80 \pm 0.02$ at.\% (i.e. 0.97 at.\% Gd and 0.83 at. $\% \mathrm{Y}$ ) and $0.40 \pm 0.03$ at.\%, and in $\alpha-\mathrm{Mg}$ are about $1.02 \pm 0.03$ at.\% (i.e. 0.70 at. $\% \mathrm{Gd}$ and 0.32 at. $\% \mathrm{Y}$ ) and $0.02 \pm 0.01$ at. $\%$ providing $\Delta H V_{\text {Seg }}=32.2 \mathrm{HV}$.

Fig. S1 summarizes the average hardness reported for a range of $\mathrm{Mg}$ alloys processed by multiple revolutions of HPT at room temperature and subsequent peak ageing. To provide a valid comparison approximating the average hardness of the samples, the hardness data plotted in Fig. S1 is chosen from the positions near the half radius of HPT-deformed disks. It is clear that HPT-processed Mg-RE alloys with refined grains exhibits enhanced peak hardness, and the present HPT-processed Mg-Gd-Y-Zn$\mathrm{Zr}$ alloy possesses a significant higher hardness than other peak-aged conventional $\mathrm{Mg}$ alloys and Mg-RE alloys. 


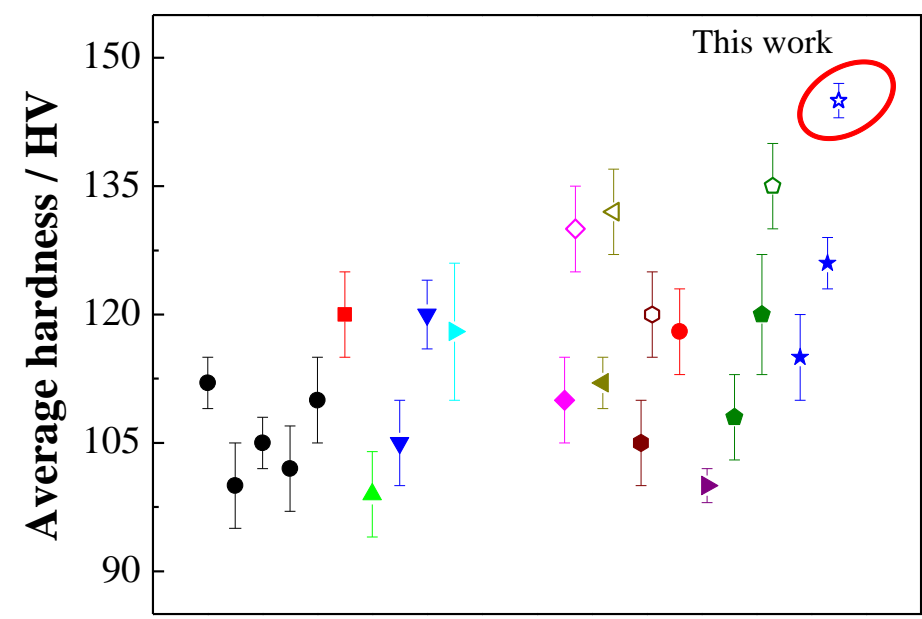

Different Mg alloys processed by HPT

- $\mathrm{Mg}-\mathrm{Al}-\mathrm{Zn}[57-62]>\mathrm{Mg}-\mathrm{Zn}-\mathrm{Zr}-\mathrm{Ca}[67]$

- $\operatorname{Mg}-\mathrm{Zn}[56] \mathrm{Mg}-\mathrm{Tb}[12]$

$\triangle \mathrm{Mg}-\mathrm{Zn}-\mathrm{Ca}[63] \diamond$ Ageing of Mg-Tb[12] $\bigcirc$ Ageing of Mg-Gd[68]

จ Mg-Zn-Zr[64-66] 4 gg-Tb-Nd[12]

$\triangleleft$ Ageing of $\mathrm{Mg}-\mathrm{Tb}-\mathrm{Nd}[12]$

Mg-Dy-Al-Zn-Zr[70]

Mg-Gd-Y-Zr[13, 71]

$\checkmark$ Ageing of Mg-Gd-Y-Zr[13]

$\star$ Mg-Gd-Y-Zn-Zr[15, 72]

This work

Fig. S1 Comparison of average hardness in different Mg alloys processed by HPT at room temperature (marked as solid symbols) and subsequently peak ageing (marked as open symbols).

For full details of compositions and processing see the cited publications [12, 13, 15, 56-72]. 